Ankara Üniversitesi Eğitim Bilimleri Fakültesi Dergisi

Yll: 2019, Cilt: 52, Sayl: 1, 139-161

DOI: 10.30964/auebfd.487428, E-ISSN: 2458-8342, P-ISSN: 1301-3718

\title{
4+4+4'ten Geriye Kalanlar: Türk Öğrencilerin Başarılarındaki Göreli Yaş Etkisi
}

\begin{tabular}{lccc}
\hline MAKALE TÜRÜ & Başvuru Tarihi & Kabul Tarihi & Erken Görünüm Tarihi \\
Araştırma Makalesi & 26.11 .2018 & 18.2 .2019 & 19.2 .2019 \\
\hline
\end{tabular}

\author{
H. Çiğdem Yavuz iD ${ }^{1}$
}

Çukurova Üniversitesi

Öz

Göreli yaş etkisinin, öğrencilerin okul başarılarında etkili olduğu birçok amprik araştırmada ortaya konulmuştur. Bu kapsamda, bu çalışmada dördüncü sınıf Türk öğrencilerinin matematik ve fen bilimleri alanlarındaki başarıları üzerinde göreli yaş etkisinin olup olmadığı ve $4+4+4$ sistemiyle bu etkinin nasıl değiștiği araştırılmıştır. Ayrıca, öğrencilerin yaşlarıyla cinsiyet, ev kaynakları ve sahip olunan kitap sayısı değişkenlerinin etkileşimi de bu çerçevede incelenmiştir. Araştırmanın çalışma grubunu Uluslararası Matematik ve Fen Bilimlerindeki Eğilimler Araştırmasına (Trends in International Mathematics and Science Study - [TIMSS]) 2011 ve 2015 yıllarında katılmış Türk öğrenciler arasından bazı ölçütlere göre belirlenen 10297 öğrenci oluşturmaktadır. Çalışmada verilerin analizinde çok değişkenli çok düzeyli modeller kullanılmıştır. Öğrenci düzeyinde, öğrencinin ay olarak sınav tarihindeki yaşı, bu değişkenin cinsiyet, ev kaynakları ve okunan kitap sayısı ile etkileşimi; okul düzeyinde ise bölge değişkeni ele alınmıştır. Bu kapsamda, çalışmada 4+4+4 öncesinde ve sonrasında da göreli yaş etkisinin öğrenci başarısında etkili olduğu fakat bu etkinin 2015 yılında daha yüksek olduğu belirlenmiştir. Başka anlatımla, diğerlerine göre okula daha erken yaşta başlayan öğrencilerin yaşlarının 2015 yılında onları daha dezavantajlı konuma getirdiği belirtilebilir. Ayrıca akademik başarı üzerinde, yaşla ev kaynakları etkileşiminin negatif, yaşla sahip olunan kitap sayısı etkileşiminin ise pozitif bir etkisinin olduğu belirlenmiştir.

Anahtar sözcükler: Göreli yaş etkisi, öğrenci başarısı, 4+4+4, TIMSS, çok değişkenli çok düzeyli modeller.

\footnotetext{
${ }^{1}$ Sorumlu Yazar: Arş. Gör. Dr., Eğitim Fakültesi, Eğitim Bilimleri Bölümü, E-posta: hcyavuz@ gmail.com, http://orcid.org/0000-0003-2585-3686
} 
Öğrencilerin doğum tarihlerinin (gün, ay ve yıl olarak) okul başarılarında etkili olduğu birçok amprik araştırmada ortaya konulmuştur (Aune, Pedersen, Ingvaldsen ve Dalen, 2017; Haunk ve Finch, 1993; Sprietsma, 2010; Thoren, Heinig ve Brunner, 2016). Bu çalışmalara göre öğrencinin okula başladığı yılın ilk aylarında doğmuş olması ilgili öğrenciye o yılın sonundaki aylarda doğmuş diğer öğrencilere göre daha üstün bir konum sağlamaktadır. Göreli yaş etkisi (relative age affect) olarak tanımlanan bu duruma öncelikli olarak spor alanındaki araştırmalarda rastlanmıştır (Barnsley, Thompson ve Barnsley, 1985; Grondin, Deshaies ve Nault, 1984). Bu çalışmalarda, ilgili takvim yılında oldukça başarılı olan buz hokeyi oyuncularının diğer oyunculara göre daha erken lige başladıkları belirlenmiştir. Göreli yaş etkisi, aynı yaştaki sporcuların gruplandırılması nedeniyle grup içindeki bireyler arasında neredeyse bir yıl kadar fark olması ve böylelikle ay olarak yaşı daha büyük olan sporcuların diğerlerine göre çok daha iyi performans göstermesi durumudur (Thompson, Barnsley ve Battle, 2004).

Okula başlama tarihinin ilgili takvim yılında her öğrenci için aynı olduğu ve öğrencilerin aynı yaşta okula başladıkları düşünüldüğünde, öğrencilerin de spor alanında olduğu gibi okullarda da gruplandırılmış oldukları bilinmektedir. Öğrencilerin yaşı aynı olsa da öğrencinin doğduğu ay onu diğer öğrencilere "görece" daha avantajlı ya da dezavantajlı konuma getirebilmektedir (Haunk ve Finch, 1993). Böylece spor alanında ortaya çıkan göreli yaş etkisi, benzer şekilde eğitimde de görülmektedir (Aune, Pedersen, Ingvaldsen ve Dalen, 2017; Huang, 2015; Sprietsma, 2010; Thoren, Heinig ve Brunner, 2016; Verachtert, De Fraine, Onghena ve Ghesquière, 2010).

Alanyazında birçok farklı ülkede öğrencilerin başarılarındaki yaş etkisi kesitsel olarak incelenmiştir. Örneğin, 4. sınıf Hırvat öğrencilerle yapılan bir çalışmada yaşı büyük olan öğrencilerin her alanda akademik başarılarının yaşı küçük olan öğrencilere göre daha yüksek olduğu fakat göreli yaş etkisinin zayıf olduğu belirlenmiştir (Sakic, Burusic ve Babarovic, 2013). Aynı çalışmada, sekizinci sınıf Hırvat öğrencilerde ise göreli yaş etkisine rastlanmamıştır. Thoren, Heinig ve Brunner (2016) çalışmalarında, Alman öğrencilerin başarılarında göreli yaş etkisinin olduğunu fakat sınıf düzeyi arttıkça bu etkinin azaldığını ortaya koymuştur. Ayrıca, aynı çalışmada göçmen öğrenciler üzerinde göreli yaş etkisinin Alman öğrencilere göre daha yüksek olduğu belirlenmiştir. Norveçli öğrenciler üzerinde yapılan bir çalışmada da akademik başarı üzerinde göreli yaş etkisi bulunmuş, bu etkinin erkek öğrencilere göre kız öğrenciler üzerinde daha yüksek olduğu belirlenmiştir (Aune, Pedersen, Ingvaldsen ve Dalen, 2017). Bedard ve Dhuey (2006) tarafından 19 ülkenin karşılaştırıldığı çalışmalarında sadece Danimarka ve Finlandiya'da göreli yaş etkisinin bulunmadığı ortaya konulmuştur. Norbury, Gooch, Baird, Charman, Simonoff ve Pickles (2016) de davranışsal ve dilsel gelişim üzerinde göreli yaş etkisini araştırmış ve diğer çalışmalarla benzer bulguları elde etmiştir. Çalışmaya göre daha küçük yaşta olan öğrencilerin akademik yeterlikleri sağlamada sorun yaşadıkları görülmüştür. Sprietsma'nın (2010) 34 ülkedeki öğrencileri yaşlarına göre karş̧laştırıldı̆̆ çalışmasında da göreli yaş etkisinin okuduğunu anlama ve matematik başarısında 
etkili olduğu belirlenmiştir. İlgili çalışmaya göre göreli yaş etkisinin doğrusal olmadığı da ortaya konulmuştur.

Bazı çalışmalarda ise boylamsal olarak göreli yaş etkisi incelemiştir (Verachtert, De Fraine, Onghena ve Ghesquière, 2010). Bu çalışmaya göre yılın ilk üç ayında doğan Belçikalı birinci sınıf öğrencilerinin matematik alanında daha başarılı olduğu fakat iki yıl sonrasında, bu grupla diğer öğrenciler arasındaki başarı farklarının azaldığı belirlenmiştir. Diğer bir boylamsal çalışmada da (Huang, 2015) öğrencilerin yetenekli öğrenci gruplarına seçilmesinde göreli yaş etkisinin olup olmadığı araştırılmıştır. Bu çalışmaya göre öğrencilerin yetenekli gruba seçilmesi ile göreli yaş etkisi arasında zayıf bir ilişkinin olduğu belirlenmiştir. Ayrıca, 21260 öğrencinin anaokulundan sekizinci sınıfa kadar olan başarıları üzerindeki göreli yaş etkisinin incelendiği bir diğer boylamsal çalışmada (Zhong, 2012), göreli yaş etkisinin üçüncü sınıfa kadar etkili olduğu belirlenmiştir. Bununla birlikte, diğer boylamsal çalışmalarda olduğu gibi bu etkinin diğer sınıf düzeylerine doğru azaldığı ortaya konmuştur.

Göreli yaş etkisinin öğrencilerin eğitim yaşamlarında alınan kararlarda etkili olduğu görülmektedir. Bunlardan bazıları öğretmenlerin yanlı davranmalarından kaynaklanabilmektedir (Norbury ve diğ., 2016). Örneğin Gledhill, Ford ve Goodman'ın (2002) çalışmasına göre öğretmenler tarafindan yapılan değerlendirmelerde, yılın ilk üç ayında doğmuş öğrencilerin yetenekli sınıf gruplarında yer alma olasılığının daha yüksek olduğu; yılın sonlarında doğmuş öğrencilerin ise öğrenme güçlüğü çeken öğrenci grubunda olması olasılığının daha yüksek olduğu belirlenmiştir. Benzer bulgulara Aune ve diğ. (2017) ile Wilson (2000) da ulaşmıştır. Bu anlamda, bulundukları grupta ay olarak küçük olan öğrencilerin, ay olarak onlara göre daha büyük öğrencilere göre zorluk çektiği durumlarda öğretmenlerin yanlı olabileceği belirlenmiş̧ir.

Alanyazında, göreli yaş etkisinin ortaya çıkmasındaki nedenler olarak grubun birbirine göre zeka, olgunluk (maturity), potansiyel bakımından farklı düzeylerde olması savunulmaktadır (Sykes, Bell ve Rodeiro, 2009). Bu nedenlerden dolayı ortaya çıkan bu farklılıklar alanyazında öğrencilerin cinsiyetine ya da sosyokültürel/sosyoekonomik konumuna göre de değişiklik göstermektedir (Aune ve diğ., 2017; Borg ve Falzon, 1995; Musch ve Hay, 1999; Solli, 2017; Wilson, 2000; Zhong, 2012). Çalışmaların bulguları göreli yaş etkisi ile cinsiyet etkileşiminin, sınıf düzeylerine göre farklılaştığını ortaya koymaktadır. Bunun yanında, sosyokültürel/sosyoekonomik özelliklerin öğrencilerin yaşlarından meydana gelen farkl1lıklar üzerinde önemli rolü olduğu görülmektedir. Okula başlamadan önce öğrencilerin fiziksel, sosyal ve psikolojik gelişimlerinde söz konusu özelliklerin destekleyici olması, bu durumun nedenleri arasında görülebilir. Örneğin, göreli yaş etkisinin sosyoekonomik düzeyi yüksek olan öğrenciler üzerinde çok fazla olumsuz etkiye neden olamayacağı belirtilmektedir (Bedard ve Dhuey, 2006).

Alanyazındaki çalışmaların ortaya koyduğu bilgiler kapsamında, okullara başlama dönemi ve öğrencilerin eğitime ne zaman başlaması gerektiği konusu 
tartışmalara konu olmuştur (Haunk ve Finch, 1993). Türkiye'de de uzun yıllar öğrencilerin okula başlaması için belirlenen sınır 72 ay iken, 2012'de bu 66 aya indirilmiştir (Milli Eğitim Bakanlığı [MEB], 2012). Bu uygulamayla birlikte, Türkiye'de zorunlu eğitim de $4+4+4$ olmak üzere üç kademeye ayrılmıştır. Bu uygulama ile birlikte eğitim sistemindeki paydaşlar tarafindan yaşanılan zorluklar ve olumsuzluklar birçok araştırmada ortaya konulmuştur (Cerit, Akgün, Yıldız ve Soysal, 2014; Doğan, Uğurlu ve Demir, 2014; Epçaçan, 2014; Memişoğlu ve İsmetoğlu, 2013). Bu çalışmalara göre yapılan bu değişiklikler, öğretmenler açısından genel olarak öğrencilerin hazır bulunuşluk (bilişsel, dilsel ve psikolojik) düzeylerinin yetersiz olması, öğrencilerin uyum sorunu yaşaması, öğretim programının ilgili değişikliğe uygun olmaması; yöneticiler açısından ise ilgili değişikliklerle beraber ortaya çıkan (okul ortamının yetersiz olması, ders giriş-çıkış saatlerinde farklılıkların ortaya çıkması vb.) yetersizlik sorunlarını ortaya çıkarmıştır.

Eğitim kademelerinin bölünmesi ve eğitime başlama yaşının değiştirilmesiyle en çok öğrencilerin etkilenmiş olduğu belirtilebilir. Özellikle ilköğretime başlama yaşına ilişkin yapılan değişiklik, Güven'in (2012) de belirttiği üzere öğrenciler üzerinde geriye dönülemeyecek bazı zararlara yol açacak niteliktedir. Bu zararların nedenlerinden biri de göreli yaş etkisi olabilir. Ulusal alanyazın taraması yapıldığında göreli yaş etkilerinin öğrenci başarılarındaki rolü hakkında herhangi bir çalışmaya rastlanmamıştır. Öğretmenler için okula yeni başlayan öğrencilerin öğrenme sürecinde yaşadıkları sorunların, onların yaşlarından mı yoksa becerilerindeki yetersizlikten mi kaynaklandığını bulabilmek bile zor iken (Allen ve Barnsley, 1993), $4+4+4$ ile bunun daha da karmaşık duruma gelmiş olması olasıdır. Ayrıca, göreli yaş etkisinin öğrencilerin yaşamları boyunca etkili olabileceği (Sprietsma, 2010) göz önüne alındığında da Türk öğrencilerin başarılarında göreli yaş etkisinin olup olmadığını ortaya koyabilmenin özellikle ulusal alanyazın için ve eğitim paydaşları için önemli olduğu düşünülmektedir.

Bu amaçla, çalışmada Türk öğrencilerinin başarıları üzerinde göreli yaş etkisinin olup olmadığı Uluslararası Matematik ve Fen Bilimlerindeki Eğilimler Araştırmasının (Trends in International Mathematics and Science Study - [TIMSS]) dördüncü sınıf uygulamaları kapsamında incelenmiştir. TIMSS uygulamalarında, dünyadaki birçok ülkedeki sekizinci ve dördüncü sınıftaki öğrencilerin dört yılda bir matematik ve fen bilimlerindeki başarıları belirlenmektedir. Bu çalışmanın TIMSS'in dördüncü sınıf uygulamaları kapsamında olmasının nedeni, $4+4+4$ ile eğitim kademelerinin dördüncü sınıfta ayrılmış olması ve TIMSS uygulamalarının $4+4+4$ öncesi ile karşılaştırmaya olanak vermesidir. Özetle bu çalışmada, okula başlama yaşının 72 aylık olduğu dönemde okula başlamış olup 2011'de dördüncü sınıfta TIMSS 2011'e katılmış öğrenciler ile $4+4+4$ kapsamında okula başlama yaşının 66 aylık olduğu dönemde okula başlamış olup 2015'te dördüncü sınıfta TIMSS 2015'e katılmış öğrencilerin başarılarındaki göreli yaş etkisi araştırılmıştır. Ayrıca öğrencilerin yaşlarıyla cinsiyet, sosyokültürel düzeye ilişkin bilgi veren ev kaynakları ve sahip olunan kitap sayısı değişkenlerinin etkileşiminin öğrenci başarısı üzerindeki etkisi incelenmiştir. $\mathrm{Bu}$ amaçla çalışmada şu sorulara yanıt aranmıştır: (i) Öğrencilerin 
TIMSS 2011 ile TIMSS 2015 matematik ve fen bilimleri başarılarında göreli yaş etkisi bulunmakta mıdır? (ii) Öğrencilerin yaşlarıyla cinsiyet, ev kaynakları ve sahip olunan kitap sayısı değişkenleri arasındaki etkileşim, TIMSS 2011 ile TIMSS 2015 matematik ve fen bilimleri başarıları üzerinde manidar bir etkiye sahip midir?

\section{Yöntem}

$\mathrm{Bu}$ başlık altında araştırma modeli, çalışma grubu, veri toplama araçları ve verilerin analizi ile ilgili bilgiler ele alınmıştır.

\section{Araştırma Modeli}

$\mathrm{Bu}$ araştırma ilişkisel araştırma modelinde bir araştırmadır (Lodico, Spaulding ve Voegtle, 2006). Çünkü bu araştırma öğrencilerin yaşlarıyla matematik ve fen bilimleri alanındaki başarıları arasındaki ilişki incelenmiştir.

\section{Çalışma Grubu}

Araştırmanın çalışma grubunu TIMSS 2011 ve TIMSS 2015'e katılmış Türk öğrenciler arasından yaşlarına göre seçilen öğrenciler oluşturmaktadır. Çalışma grubunun belirlenmesinde öğrencilerin ay olarak hesaplanan yaşları temel alınmıştır. Bunun için dördüncü sınıfta okuyan öğrencilerin TIMSS 2011 ve TIMSS 2015 uygulamalarına katılabilecekleri en erken yaş ile en geç yaş hesaplanmıştır. TIMSS 2011 'deki öğrenciler için ilgili yaş aralığ 1 şu şekildedir:

TIMSS 2011 Türkiye eğitim programı anketinde yer alan bilgiye göre (TIMSS 2011 Fourth Grade Curriculum Questionnaire Data, https://timssandpirls.bc.edu/timss2011/international-database.html) “Öğrencilerin ilgili takvim yılında Eylül’de okula başlamaları için öğrencinin, o yılın Aralık ayının sonunda 72 ayı doldurması gerekmektedir. Fakat velilerin isteği doğrultusunda öğrenciler bir yıl sonra okula başlayabilirler.” Bu bilgi 1şı̆̆ında, TIMSS 2011'de dördüncü sınıf öğrencilerin en erken okula başlayanı Aralık 2007'de 6 yaşına (72 ay) girip 2007 Eylül'de okula gitme hakkı kazanan öğrencilerdir. Bu öğrenciler okula 68 aylıkken en erken okula başlamış öğrencilerdir. Bu grupta en geç okula başlama yaşı ise 2007 Ocak'ta 6. yaşına girip Eylül'de okula 80 aylık iken başlayan öğrencilerdir. Velilerin öğrencileri bir yıl sonra okula başlatması alanyazında "redshirting" olarak tanımlanmaktadır. $\mathrm{Bu}$ öğrenciler olması gerekenden daha büyük yaşta okula başladıkları için bu öğrencilerin diğer öğrencilere göre akademik açıdan daha avantajlı olabildikleri (Frey, 2005) bilinmektedir. Bu nedenle bu öğrenciler çalışma kapsamına alınmamıştır. Bu durumda, bu çalışma için normal koşullarda en geç okula başlamış öğrenciler 80 aylık olan öğrenciler olarak kabul edilmiştir. Özetle, TIMSS 2011 için çalışmaya 68-80 ay aralığında okula başlamış öğrenciler dahil edilmiştir. TIMSS 2015'teki öğrenciler için yaş aralığı ise şu şekilde hesaplanmıştır:

TIMSS 2015 eğitim programı anketinde (TIMSS 2015 Fourth Grade Curriculum Questionnaire Data, https://timssandpirls.bc.edu/timss2015/international-database/) yer alan bilgiye göre "Öğrenciler Eylül'de okula başlamak için 5.5 yaşında olmalıdırlar. Fakat veliler tercih ederse 5.5-6 yaşında olan öğrencilerin okula kayıt 
olmasını bir yıl erteleyebilirler.” Bu kapsamda 2015'te dördüncü sınıfta öğrenim gören öğrencilerinden en erken okula başlayanlar, Eylül 2011'de 66 aylık (5.5 yaş) olan öğrencilerdir. Bu grupta en geç okula başlayan öğrenciler ise 2011 Ocak'ta 5.5 yaşını doldurup Eylül'de 74 aylıkken okula başlayan öğrencilerdir. Bu durumda, bu çalışma için normal koşullarda en geç okula başlamış öğrenciler 74 aylık olan öğrenciler olarak kabul edilmiştir. Özetle, TIMSS 2015 için bu çalışmaya 66 - 74 ay aralığında okula başlamış öğrenciler dahil edilmiştir.

TIMSS uygulamaları Türkiye'de Nisan sonu/Mayıs başı olarak uygulandığından, testin yapılma tarihi olarak her iki uygulamada da Mayıs ayı kabul edilmiştir. Böylelikle test yapılma tarihinde öğrencilerin kaç aylık olduklarını hesaplamak için öğrencilerin hesaplanan yaşlarına 45 ay $(4$ ay +12 ay +12 ay +12 ay +5 ay) eklenmiştir. Bu işlem sonrasında belirlenen yaş aralıklarına göre çalışmaya dahil edilen öğrencilere ilişsin bilgiler Tablo 1'de verilmiştir.

Tablo 1

Çalışmaya Dahil Edilen Öğrenciler ve Özellikleri

\begin{tabular}{lcc}
\hline & $\begin{array}{c}\text { Belirlenen Yaş Aralığında } \\
\text { Olan Öğrenciler }\end{array}$ & $\begin{array}{c}\text { Belirlenen Yaş Aralığı } \\
\text { Dışında Kalan Öğrenciler }\end{array}$ \\
\hline $\begin{array}{l}\text { TIMSS 2011 } \\
(113-125 \text { aylık })\end{array}$ & $5742(\% 50.1 \mathrm{kız})$ & 1737 \\
\hline $\begin{array}{l}\text { TIMSS 2015 } \\
(111-119 \text { aylık })\end{array}$ & $4555(\% 49.9 \mathrm{kiz})$ & 2396 \\
\hline Toplam & 10297 & 3638 \\
\hline
\end{tabular}

Tablo 1'e göre TIMSS 2015'te çalışma dışında bırakılan öğrencilerin sayısı TIMSS 2011'e göre daha yüksektir. Bunun yanında, çalışmaya dahil edilen öğrencilerin cinsiyet açısından da birbirine yakın olduğu söylenebilir.

\section{Veri Toplama Araçları}

Çalışmaya ilişkin veriler, TIMSS 2011 ve 2015 (http://timssandpirls.bc.edu) uygulamasında yer alan öğrenci anketi, matematik ve fen başarı testlerine ilişkin verilerden elde edilmiştir.

Matematik ve fen bilimleri başarı testi. Bu çalışmada öğrencilerin başarıları TIMSS 2011 ve 2015'te dördüncü sınıf öğrencilerine uygulanan matematik ve fen bilimleri başarı testlerinden elde edilen puanlardır. TIMSS 2011 ve 2015 raporlarına göre (Martin ve Mullis, 2012; Martin, Mullis ve Hooper, 2016) matematik başarı testlerindeki maddeler, sayılar (\% 50), geometrik şekil ve ölçüler (\% 35$)$, veri gösterimi ( $\%$ 15) konularından oluşmaktadır. Fen bilimleri başarı testlerindeki maddeler, canlı bilimleri (\% 45), fiziksel bilimler (\% 35) ve yer bilimleri (\% 20) konularından oluşmaktadır. Her iki alanda yer alan maddelerin bilişsel alanların \% 40’’ bilme, diğer \% 40'1 uygulama, kalan \% 20'si ise akıl yürütme şeklindedir. 
Öğrenci anketi. Araştırmada öğrencilere ilişkin diğer veriler TIMSS 2011 ve 2015 uygulamalarındaki öğrenci anketlerinden elde edilmiştir. Çalışma kapsamında öğrenci değişkenleri olarak öğrencinin yaşı (sürekli değişken), cinsiyeti $(0=\mathrm{k} 1 z$, $1=$ erkek), ev kaynakları (indeks değişkeni), evde bulunan kitap sayısı (0-10=0, 11$25=1,26-100=2,101-200=3,200+=4$ ) ele alınmıştır.

Okul anketi. Çalışmada okulların ait olduğu bölge kodları TIMSS 2011 uygulamasında okul anketinden, TIMSS 2015 uygulamasındaki ise Milli Eğitim Bakanlığından resmi izin ile alınmıştır. Bölge değişkeni Marmara, Ege, Doğu Anadolu, Güneydoğu Anadolu, İç Anadolu, Karadeniz ve Akdeniz bölgesi olarak 7 kategoriden oluşan bir değişken olarak ele alınmıştır. TIMSS 2015 uygulamasında TIMSS 2011'den farklı olarak “Türkiye geneli kırsal” bölgesi de bulunmaktadır.

\section{Verilerin Analizi}

Çalışmada veri analizi öncesinde veri setlerinin hazır duruma getirilmesinde çeşitli işlemler yapılmıştır. Öncelikli olarak, her bir TIMSS uygulaması için ev kaynakları değişkeni (homei) için yeni bir indeks değişken oluşturulmuştur. Bu işlem için Ekonomik Kalkınma ve İşbirliği Örgütünün (The Organisation for Economic Cooperation and Development [OECD]) PISA'da kullandığ 1 indeks formülü (OECD, 2014, s. 352) kullanılmıştır. TIMSS'de öğrencilerin ev kaynaklarına ilişkin olan 10 madde ile her bir yıl için söz konusu bu indeks değişkeni, temel bileşen analiz yardımı ile oluşturulmuştur.

Çalışmaya dahil edilen öğrencilerin sınava girdikleri yaş değişkeni (agem) hesaplanmıştır. Bunun için öğrencilerin yaşı (AGE) 12 ile çarpılmıştır. Böylece çalışmanın göreli yaş etkisinin inceleneceği yaş değişkeni (agem) oluşturulmuştur.

Verilerin analizinde çok değişkenli çok düzeyli modeller (multivariate multilevel modeling) (Heck ve Thomas, 2015) kullanılmıştır. Bu modellerle hiyerarşik yapıda olan ve birden fazla bağımlı değişkenin olduğu veri setlerinde daha düşük hata ile kestirim yapılabilmektedir (Heck ve Thomas, 2015). Çalışma kapsamına dahil edilen okullardan 12'den daha az öğrencisi olan okullar analize alınmamıştır. Bunun nedeni, Browne ve Draper'a göre (2006) 12 birimden daha az birimi olan kümelerin dahil edildiği çok düzeyli modellerin parametre kestirimlerinin doğru bir şekilde hesaplanamamasıdır. Bu kapsamda, TIMSS 2011'de 29 okul; TIMSS 2015'te 52 okul analiz dışı bırakılmıştır.

Çalışmada analizlerin tümü Mplus 8 (Muthén ve Muthén, 1998, 2017) programı kullanılarak yapılmıştır. Mplus programında Full Information Maximum Likelihood (FIML) kestirim yöntemi kullanılmasından dolayı kayıp veriler üzerinde herhangi bir işlem yapılmamıştır. Sadece veri setinde tüm kayıp veriler 999 ile kodlanmıştır. Mplus'ın kullandığı FIML kesitirim yöntemi kayıp verilerin olduğu veri setlerinde güçlü bir seçenek sunmaktadır (Muthén ve Muthén, 1998, 2017). Verilerin analizinden önce değişkenlere ilişkin varsayımlar (düzey 1 için hataların normalliği, düzey 1 varyansların homojenliği, düzey 2 değişkenlerinin normallik varsayımı) Q- 
Q, histogram, saçılma grafiklerinden ve ki-kare istatistiğinden yararlanılarak incelenmiş ve varsayımların karşılandığı görülmüştür.

Çalışmada bağımlı değişkenler, matematik ve fen bilimleri başarı testlerinde öğrencilerin aldıkları puanlardır. TIMSS uygulamalarında matematik ve fen bilimleri testlerinde öğrencilerin beş farklı puanı (plausible value) hesaplanmaktadır. Bu çalışmada da her bir test için belirlenen bu beş değişken aynı anda analize alınmıştır. Bu amaçla, Mplus'ın “imputation” komutu kullanılmıştır.

Çalışma için kurulan modellerde öğrenci ve okul düzeyi alınmıştır. Öğrenci düzeyinde, öğrencinin ay olarak yaşı (agem), bu değişkenin cinsiyet (agem*ITSEX), ev kaynakları (agem*homei) ve okunan kitap sayısı (agem*ASBG04) ile etkileşimi ele alınmıştır. Okul düzeyinde ise modele okulların ait olduğu bölge değişkeni kategorik değişken olarak alınmıştır. TIMSS 2015'te bölge kodlarından biri "kırsal" olarak verilmektedir. Bu kodla birlikte Türkiye'de bulunan tüm bölgelerdeki kırsal alanlardan seçilen okullar tanımlanmıştır. Bu kod TIMSS 2011'de tanımlanmadığından TIMSS 2015 'teki kırsal bölge koduna sahip okulların bölge değişkeni kayıp veri olarak analize alınmıştır.

$\mathrm{Bu}$ çalışmanın amacına uygun olarak çok değişkenli iki düzeyli regresyon modeli (two level regression model), çok düzeyli modellerden sonuçların ortalamalar olduğu regresyon (means-as-outcomes models), birinci düzey tesadüfi kesişim modeli (level-1 random-intercept model) ile sabit ve eğim katsayılarının çıktı olduğu model (intercepts and slopes-as-outcomes model) analiz edilmiştir. Her yıl için analiz ayrı ayrı yapılmıştır. Değişkenlere ilişkin etki büyüklüğü yerine, değişkenlerin bağımlı değişkeni yordamadaki önemini gösteren, 0-1 aralığında değişen Pratt indeksi (Liu, Zumbo ve Wu, 2014) hesaplanmıştır.

\section{Bulgular}

Çalışma kapsamına alınan öğrencilerin TIMSS 2011'de ortalama matematik başarı puanı 480.12 iken, ortalama fen bilimleri başarı puanı 473.24 olarak bulunmuştur. TIMSS 2015 'te ise ortalama matematik başarı puanı 482.42 iken, ortalama fen bilimleri başarı puanı 482.23 olarak hesaplanmıştır. Yapılan çok değişkenli iki düzeyli regresyon modeli sonuçları kapsamında, TIMSS 2011 ve 2015 'te matematik başarısı ve fen bilimleri başarısı açısından okullar arasında manidar fark bulunmuştur ( $<$ <.05). TIMSS 2011'de matematik alanında okul-içi değişimin varyans1 5631.92, okullar-aras1 değişim 3043.71, grup-içi korelasyon katsayısı .34; fen bilimleri alanında okul-içi değişimin varyansı 5464.26, okullar-arası değişim 2898.29, grup-içi korelasyon katsayısı .33 bulunmuştur. TIMSS 2015 'te matematik alanında okul-içi değişimin varyansı 5420.36, okullar-arası değişim 3321.68, grup-içi korelasyon katsayısı .38; fen bilimleri alanında okul-içi değişimin varyansı 5343.47, okullar-arası değişim 2813.29, grup-içi korelasyon katsayısı .35 bulunmuştur. Sonuçların ortalamalar olduğu regresyon modeline yönelik bulgular Tablo 2'de verilmiştir. 
Tablo 2

Sonuçların Ortalamalar Olduğu Regresyon Modeline Yönelik Bulgular

\begin{tabular}{|c|c|c|c|c|c|}
\hline $\begin{array}{l}\text { Bağımlı } \\
\text { Değişken }\end{array}$ & Değişken & Yıl & Katsayı & $\begin{array}{r}\text { Standart } \\
\text { Hata }\end{array}$ & $\begin{array}{r}\text { Katsayı/ } \\
\text { Standart Hata } \\
\end{array}$ \\
\hline \multirow{2}{*}{ Matematik } & \multirow{2}{*}{ Bölge } & 2011 & $-6.49 * *$ & 2.10 & -3.10 \\
\hline & & 2015 & -4.69 & 3.09 & -1.52 \\
\hline \multirow{2}{*}{$\begin{array}{l}\text { Fen } \\
\text { Bilimleri }\end{array}$} & \multirow{2}{*}{ Bölge } & 2011 & $-7.34 * *$ & 2.02 & -3.62 \\
\hline & & 2015 & -4.74 & 2.85 & -1.66 \\
\hline \multirow{2}{*}{\multicolumn{2}{|c|}{ Matematik x Fen Bilimleri }} & 2011 & $2825.141 * *$ & 306.51 & 9.22 \\
\hline & & 2015 & $3331.67 * *$ & 557.36 & 5.98 \\
\hline $\begin{array}{l}\text { Bağımlı } \\
\text { Değişken }\end{array}$ & Tesadüfi Etki & Yıl & Katsayı & $\begin{array}{r}\text { Standart } \\
\text { Hata } \\
\end{array}$ & t-Oranı \\
\hline \multirow{4}{*}{ Matematik } & \multirow{2}{*}{ Okul düzeyi } & 2011 & $2942.06 * *$ & 370.59 & 7.94 \\
\hline & & 2015 & $3626.11 *$ & 629.20 & 5.76 \\
\hline & \multirow{2}{*}{ Öğrenci düzeyi } & 2011 & $5561.69 * *$ & 155.90 & 35.67 \\
\hline & & 2015 & $5247.35 * *$ & 204.84 & 25.62 \\
\hline \multirow{4}{*}{$\begin{array}{l}\text { Fen } \\
\text { Bilimleri }\end{array}$} & \multirow{2}{*}{ Okul düzeyi } & 2011 & $2714.29 * *$ & 377.07 & 7.20 \\
\hline & & 2015 & $3062.96^{*}$ & 581.62 & 5.27 \\
\hline & \multirow{2}{*}{ Öğrenci düzeyi } & 2011 & $5401.03 * *$ & 182.10 & 29.66 \\
\hline & & 2015 & $5096.31 * *$ & 228.71 & 22.28 \\
\hline
\end{tabular}

$* \mathrm{p}<.05, * * \mathrm{p}<.01$

Tablo 2'ye göre TIMSS 2011 uygulamasında da okulların bulunduğu bölgelerin hem matematik hem de fen bilimleri alanındaki başarısı üzerindeki etkisinin manidar olduğu; TIMSS 2015 uygulamasında ise manidar bir etkinin olmadığı görülmektedir. $\mathrm{Bu}$ durumun nedeni TIMSS 2015'te kırsal bölge kodunun kayıp veri olarak analize alınması olabilir. Tesadüfi kesişim modeline ilişkin bulgular Tablo 3 'te verilmiştir.

Tablo 3'e göre her iki TIMSS uygulamasında da öğrencilerin göreli yaş etkisinin hem matematik hem de fen bilimleri alanındaki başarısında manidar olduğu görülmektedir ( $\mathrm{p}<.05)$. TIMSS 2011'de göreli yaş etkisinin matematik alanındaki pratt indeksi 0.04 iken fen bilimleri alanındaki pratt indeksi 0.03 olarak bulunmuştur. $\mathrm{Bu}$ değerlere göre pratik anlamda göreli yaş etkisinin her iki alanda da önemli olmadığı belirtilebilir. TIMSS 2015 'te ise göreli yaş etkisinin matematik alanındaki pratt indeksi 0.13 iken fen bilimleri alanındaki pratt indeksi 0.18 olarak bulunmuştur. 
Tablo 3

Tesadüfi Kesișim Modeline İlișkin Bulgular

\begin{tabular}{|c|c|c|c|c|c|c|}
\hline $\begin{array}{l}\text { Bağımlı } \\
\text { Değişken }\end{array}$ & Değişken & Yll & Katsayı & $\begin{array}{r}\text { Standart } \\
\text { Hata }\end{array}$ & $\begin{array}{r}\text { Katsayı/ } \\
\text { Standart } \\
\text { Hata } \\
\end{array}$ & $\begin{array}{r}\text { Pratt } \\
\text { İndeksi }\end{array}$ \\
\hline \multirow{8}{*}{ Matematik } & \multirow{2}{*}{ Yaş } & 2011 & $1.42 * *$ & 0.32 & 4.47 & .04 \\
\hline & & 2015 & $3.48 * *$ & 0.62 & 5.62 & .13 \\
\hline & Yaş* $\mathrm{x}$ & 2011 & 0.03 & 0.02 & 1.32 & - \\
\hline & Cinsiyet & 2015 & $0.07 *$ & 0.02 & 2.84 & .03 \\
\hline & Yaş x Ev & 2011 & $-0.19 * *$ & 0.03 & -5.51 & .27 \\
\hline & kaynakları & 2015 & $-0.19 * *$ & 0.04 & -4.50 & .19 \\
\hline & Yaş x Kitap & 2011 & $0.10 * *$ & 0.01 & 10.11 & .50 \\
\hline & say1s1 & 2015 & $0.12 * *$ & 0.02 & 8.14 & .46 \\
\hline \multirow{8}{*}{$\begin{array}{l}\text { Fen } \\
\text { Bilimleri }\end{array}$} & \multirow{2}{*}{ Yaş } & 2011 & $1.21 *$ & 0.38 & 3.19 & .03 \\
\hline & & 2015 & $3.82 * *$ & 0.63 & 6.09 & .18 \\
\hline & \multirow{2}{*}{ Yaş x Cinsiyet } & 2011 & 0.01 & 0.02 & 0.32 & - \\
\hline & & 2015 & $0.06^{*}$ & 0.03 & 2.22 & .05 \\
\hline & Yaş x Ev & 2011 & $-0.19 * *$ & 0.03 & -6.14 & .32 \\
\hline & kaynakları & 2015 & $-0.17 * *$ & 0.04 & -3.99 & .16 \\
\hline & Yaş x Kitap & 2011 & $0.09 * *$ & 0.01 & 7.44 & .45 \\
\hline & say1s1 & 2015 & $0.11 * *$ & 0.01 & 7.72 & .42 \\
\hline \multirow{2}{*}{\multicolumn{2}{|c|}{ Matematik x Fen Bilimleri }} & 2011 & $4229.30 * *$ & 152.43 & 27.75 & - \\
\hline & & 2015 & $4266.10 * *$ & 187.29 & 22.78 & - \\
\hline $\begin{array}{l}\text { Bağımlı } \\
\text { Değiş̧ken }\end{array}$ & Tesadüfi Etki & Yll & Katsayı & $\begin{array}{r}\text { Standart } \\
\text { Hata }\end{array}$ & t-Oranı & \\
\hline \multirow{4}{*}{ Matematik } & \multirow{2}{*}{ Okul düzeyi } & 2011 & $1286.89 * *$ & 253.65 & 5.07 & \\
\hline & & 2015 & $1215.82 *$ & 385.32 & 3.15 & \\
\hline & \multirow{2}{*}{$\begin{array}{l}\text { Öğrenci } \\
\text { düzeyi }\end{array}$} & 2011 & $5442.23 * *$ & 170.67 & 31.88 & \\
\hline & & 2015 & $5100.70 * *$ & 243.31 & 20.75 & \\
\hline \multirow{4}{*}{$\begin{array}{l}\text { Fen } \\
\text { Bilimleri }\end{array}$} & \multirow{2}{*}{ Okul düzeyi } & 2011 & $1221.64 * *$ & 267.95 & 5.07 & \\
\hline & & 2015 & $997.09 *$ & 335.14 & 2.97 & \\
\hline & Öğrenci & 2011 & $5277.43 * *$ & 182.27 & 28.95 & \\
\hline & düzeyi & 2015 & $5049.21 * *$ & 243.32 & 20.75 & \\
\hline
\end{tabular}

Öğrencilerin yaş ile cinsiyetleri arasındaki etkileşimin TIMSS 2015 matematik ve fen başarıları üzerinde manidar bir etkisinin olduğu görülmektedir. Buna göre TIMSS 2015'te yaşı ay olarak büyük olan erkek öğrencilerin matematik ve fen alanındaki başarısı, yaşı ay olarak büyük olan kız öğrencilere göre daha yüksek olduğu belirtilebilir. Bununla birlikte ilgili etkileşim değişkenin pratt indeks değeri incelendiğinde elde edilen manidar etkinin pratik anlamda önemli olmadığı belirtilebilir. Her iki TIMSS uygulamasında, yaşla ev kaynaklarının ve sahip olunan kitap sayısının etkileşiminin her iki alan üzerindeki başarıya manidar etkisinin olduğu 
belirlenmiştir. Tablo 4'te sabit ve eğim katsayılarının çıktı olduğu modele yönelik bulgular verilmiştir.

Tablo 4

Sabit ve Ĕgim Katsayılarının Çıktı Olduğu Modele Yönelik Bulgular

\begin{tabular}{|c|c|c|c|c|c|c|}
\hline $\begin{array}{l}\text { Bağımlı } \\
\text { değişken }\end{array}$ & Değişken & Yil & Katsayı & $\begin{array}{r}\text { Standart } \\
\text { Hata }\end{array}$ & $\begin{array}{r}\text { Katsayı/ } \\
\text { Standart } \\
\text { Hata } \\
\end{array}$ & $\begin{array}{r}\text { Pratt } \\
\text { İndeksi }\end{array}$ \\
\hline \multicolumn{7}{|c|}{ Öğrenci düzeyi } \\
\hline \multirow{8}{*}{ Matematik } & \multirow{2}{*}{ Yaş } & 2011 & $1.32 * *$ & 0.32 & 4.16 & .06 \\
\hline & & 2015 & $3.32 * *$ & 0.67 & 4.99 & .17 \\
\hline & Yaș $\mathrm{x}$ & 2011 & 0.03 & 0.02 & 1.46 & - \\
\hline & Cinsiyet & 2015 & $0.08^{*}$ & 0.03 & 2.85 & .06 \\
\hline & Yaş x Ev & 2011 & $-0.12 * *$ & 0.03 & -3.96 & .27 \\
\hline & kaynakları & 2015 & $-0.11^{*}$ & 0.04 & -2.49 & .26 \\
\hline & \multirow{2}{*}{$\begin{array}{l}\text { Yaş x Kitap } \\
\text { sayısı }\end{array}$} & 2011 & $0.09 * *$ & 0.01 & 9.43 & .66 \\
\hline & & 2015 & $0.11 * *$ & 0.02 & 7.44 & .60 \\
\hline \multirow{8}{*}{$\begin{array}{l}\text { Fen } \\
\text { Bilimleri }\end{array}$} & \multirow{2}{*}{ Yaş } & 2011 & $1.16 * *$ & 0.36 & 3.20 & .05 \\
\hline & & 2015 & $3.58 * *$ & 0.67 & 5.35 & .24 \\
\hline & Yaş $\mathrm{x}$ & 2011 & 0.01 & 0.02 & 0.42 & - \\
\hline & Cinsiyet & 2015 & $0.06^{*}$ & 0.03 & 2.07 & .05 \\
\hline & Yaş x Ev & 2011 & $-0.14 * *$ & 0.03 & -4.50 & .34 \\
\hline & kaynakları & 2015 & $-0.08^{*}$ & 0.04 & -1.99 & .12 \\
\hline & Yaş x Kitap & 2011 & $0.08 * *$ & 0.01 & 6.59 & .60 \\
\hline & say1S1 & 2015 & $0.09 * *$ & 0.01 & 7.02 & .58 \\
\hline \multirow{2}{*}{\multicolumn{2}{|c|}{ Matematik x Fen Bilimleri }} & 2011 & $4114.34 * *$ & 141.34 & 29.11 & \\
\hline & & 2015 & $3996.17 * *$ & 170.54 & 23.43 & \\
\hline \multicolumn{7}{|l|}{ Okul düzeyi } \\
\hline \multirow{2}{*}{ Matematik } & \multirow{2}{*}{ Bölge } & 2011 & $-5.59 * *$ & 1.811 & -3.09 & \\
\hline & & 2015 & -4.64 & 2.57 & -1.80 & \\
\hline \multirow{2}{*}{$\begin{array}{l}\text { Fen } \\
\text { Bilimleri }\end{array}$} & \multirow{2}{*}{ Bölge } & 2011 & $-6.12 * *$ & 1.77 & -3.46 & \\
\hline & & 2015 & -4.49 & 2.39 & -1.88 & \\
\hline \multirow{2}{*}{\multicolumn{2}{|c|}{ Matematik x Fen Bilimleri }} & 2011 & $1789.61 * *$ & 237.60 & 7.53 & \\
\hline & & 2015 & $2064.98 * *$ & 426.03 & 4.85 & \\
\hline $\begin{array}{l}\text { Bağımlı } \\
\text { Değişken }\end{array}$ & $\begin{array}{l}\text { Tesadüfi } \\
\text { Etki }\end{array}$ & Yil & Katsayı & $\begin{array}{r}\text { Standart } \\
\text { Hata } \\
\end{array}$ & t-Oranı & \\
\hline \multirow{4}{*}{ Matematik } & Okul & 2011 & $1868.69 * *$ & 238.62 & 7.83 & \\
\hline & düzeyi & 2015 & $2250.91 * *$ & 457.26 & 4.92 & \\
\hline & Öğrenci & 2011 & $5328.59 * *$ & 159.03 & 33.51 & \\
\hline & düzeyi & 2015 & $4859.60 * *$ & 188.70 & 25.75 & \\
\hline \multirow{4}{*}{$\begin{array}{l}\text { Fen } \\
\text { Bilimleri }\end{array}$} & Okul & 2011 & $1746.60 * *$ & 255.71 & 6.83 & \\
\hline & düzeyi & 2015 & $4750.46 * *$ & 228.83 & 20.76 & \\
\hline & Öğrenci & 2011 & $5167.61 * *$ & 173.87 & 29.72 & \\
\hline & düzeyi & 2015 & $1930.12 * *$ & 402.72 & 4.79 & \\
\hline
\end{tabular}

$* \mathrm{p}<.05, * * \mathrm{p}<.01$ 
Tablo 4'e göre her iki TIMSS uygulamasında göreli yaş etkisinin matematik ve fen bilimleri alanındaki başarı üzerinde manidar olduğu görülmektedir. TIMSS 2011 'de göreli yaş etkisinin matematik alanındaki pratt indeksi .06 iken fen bilimleri alanındaki pratt indeksi .05 olarak bulunmuştur. Bu değerlere göre pratik anlamda göreli yaş etkisinin her iki alanda da önemli olmadığ 1 belirtilebilir. TIMSS 2015'te ise göreli yaş etkisinin matematik alanındaki pratt indeksi .17 iken fen bilimleri alanındaki pratt indeksi .24 olarak bulunmuştur. TIMSS 2015 yılında söz konusu değişkenlere ilişkin pratt indeksinin .167'den (Liu, Zumbo ve Wu, 2014) yüksek olması göreli yaş etkisinin başarı değişkeni açısından önemli olduğunu göstermektedir. Bu kapsamda TIMSS 2015'te öğrencinin diğer öğrencilere göre bir ay daha büyük olması, ortalama matematik başarısının yaklaşık 3.32 puan artmasını, ortalama fen bilimleri başarısında ise yaklaşık 3.58 puan artmasını sağlamaktadır. Özetle, TIMSS 2011'de göreli yaş etkisinin öğrenci başarısı üzerinde manidar bir etkiye sahip olduğu fakat pratik anlamda bu etkinin önemli olmadığı belirtilebilir. Bunun yanında, TIMSS 2015'te göreli yaş etkisinin öğrenci başarısı üzerinde manidar ve önemli bir etkisinin olduğu belirtilebilir. Bu anlamda özellikle 4+4+4'le gelen uygulama kapsamında okula ay olarak daha büyük başlayan öğrencilerin diğer öğrencilere göre başarı açısından daha avantajlı olduğu belirtilebilir.

Öğrencilerin yaş ile cinsiyetleri arasındaki etkileşimin TIMSS 2015 matematik ve fen başarıları üzerinde manidar bir etkisinin olduğu görülmektedir. Buna göre TIMSS 2015'te yaşı ay olarak büyük olan erkek öğrencilerin matematik ve fen alanındaki başarısının, yaşı ay olarak büyük olan kız öğrencilere göre daha yüksek olduğu belirtilebilir. Bununla birlikte ilgili etkileşim değişkenin pratt indeks değeri incelendiğinde, elde edilen manidar etkinin pratik anlamda önemli olmadığı belirtilebilir.

Her iki TIMSS uygulamasında, yaşla ev kaynaklarının ve sahip olunan kitap sayısının etkileşiminin her iki alanda başarıya manidar etkisinin olduğu belirlenmiştir. Buna göre öğrencilerin yaşlarının ay olarak artmasıyla ev kaynaklarının da artması öğrencilerin her iki alandaki başarılarında negatif etkiye sahipken, öğrencilerin yaşlarının ay olarak artmasıyla sahip oldukları kitap sayısının da artması ögrencilerin her iki alandaki başarılarında pozitif etkiye sahiptir. Her iki etkileşim değişkeninin pratt indeks değerinin (2015 fen bilimleri alanında, yaşla ev kaynakları etkileşimi dışında) . 167 'den büyük olması, bu etkileşim değişkenlerinin öğrenci başarısında önemli olduğunu göstermektedir. Tablo 5 'te ise kurulan tüm modellere ilişkin model uyum değerleri verilmiştir. 
Tablo 5

Model Uyum Dĕgerleri

\begin{tabular}{rrrrr}
\hline & & AIC & BIC & Sample-Size Adjusted BIC \\
\hline \multirow{2}{*}{2011} & Model 1 & 127839.121 & 127878.823 & 127859.757 \\
& Model 2 & 127236.993 & 127296.546 & 127267.947 \\
& Model 3 & 114087.070 & 114185.321 & 114137.656 \\
& Model 4 & 113518.531 & 113636.432 & 113579.234 \\
\hline \multirow{3}{*}{2015} & Model 1 & 83413.881 & 83451.027 & 83431.962 \\
& Model 2 & 64802.795 & 64856.305 & 64827.709 \\
& Model 3 & 68523.775 & 68614.588 & 68566.926 \\
& Model 4 & 53568.762 & 53673.436 & 53616.246 \\
\hline
\end{tabular}

Tablo 5'te verilen değerler incelendiğinde en küçük değerlerin Model 4'te olduğu görülmektedir. Bu nedenle dördüncü modelin diğerlerine göre daha iyi uyum gösterdiği belirtilebilir.

\section{Tartışma, Sonuç ve Öneriler}

$\mathrm{Bu}$ araştırmada dördüncü sınıf Türk öğrencilerinin matematik ve fen başarıları üzerinde göreli yaş etkisinin olup olmadığ 1 ve $4+4+4$ sistemi sonrasında göreli yaş etkisinin başarı üzerindeki rolünün nasıl farklılaştığ 1 ortaya konulmuştur. $\mathrm{Bu}$ kapsamda, $4+4+4$ öncesinde ve sonrasında göreli yaş etkisinin öğrenci başarısında etkili olduğu fakat bu etkinin 2015 yılında daha yüksek olduğu belirlenmiştir. Başka anlatımla, diğerlerine göre okula daha erken yaşta başlayan öğrencilerin yaşlarının 2015 yılında onları daha dezavantajlı konuma getirdiği belirtilebilir. Bunun yanında bu araştırmada yaşla cinsiyetin, ev kaynaklarının ve sahip olunan kitap sayılarının etkileşiminin de öğrencilerin matematik ve fen başarıları üzerindeki etkisi incelenmiştir. Buna göre, matematik ve fen bilimleri alanının üzerinde yaşla ev kaynakları etkileşiminin negatif, yaşla sahip olunan kitap sayısı etkileşiminin ise pozitif bir etkisinin olduğu belirlenmiştir.

Alanyazında Türkiye gibi okul döneminin Eylül'de başladığı birçok ülkede de öğrencilerin başarıları üzerinde göreli yaşın etkisinin olduğu görülmüştür (Bedard ve Dhuey, 2006; Sprietsma, 2010; Thoren, Heinig ve Brunner, 2016). Türkiye'de göreli yaş etkisinin 2011 yılından 2015 yılına arttırmasının nedeni olarak $4+4+4$ sistemi ile gelen okula başlama yaşına ilişkin uygulama gösterilebilir. Çünkü göreli yaş etkisiyle bir grup öğrencinin dezavantajlı konumda olması, ilgili grubun fiziksel ve psikolojik olarak diğerlerine göre geride kalmış olmasından kaynaklanmaktadır (Solli, 2017; Sykes, Bell ve Rodeiro, 2009). Bu anlamda, 4+4+4'ün getirdiği yaş uygulaması ile bu gibi sorunların ortaya çıkması daha olası duruma getirmiş olabilir. Bu anlamda, bu öğrencilere yönelik yapılacak ek eğitim programları uygun olacaktır.

$\mathrm{Bu}$ araştırmada TIMSS 2011 uygulamasında yaşla cinsiyet arasında manidar bir etkileşim yokken TIMSS 2015 yılında matematik alanında manidar fakat pratik anlamda önemli olmayan etkileşim kendisini göstermiştir. Buna göre, öğrencilerin 
yaşlarının ay olarak küçük ya da büyük olması cinsiyete göre matematik ve fen bilimleri başarısı üzerinde önemli derecede bir farklılık yaratmamaktadır. Bunun nedeni öğrencilerin zihinsel gelişimlerinin cinsiyete göre farklılaşmamasından kaynaklanmış olabilir. Alanyazında ise bazı çalışmalarda cinsiyet ile yaş arasında herhangi bir manidar ilişkiye rastlanmazken (Haunk ve Finch, 1993; Solli, 2017), bazı çalışmalarda göreli yaş etkisinin kızlar üzerinde daha etkili olduğu (Aune ve diğ., 2015; Borg ve Falzon, 1995; Smith, 2009) görülmüştür.

Bu araştırmada yaşla ev kaynakları arasında negatif etkileşimin olması, özellikle Türk öğrencilerin başarıları ile ters ilişki gösterebilecek ev kaynakları (internet vb.) nedeniyle olabilir. $\mathrm{Bu}$ durum ulusal alanyazındaki bazı çalışmalar tarafından da desteklenmektedir (Güvendir, 2017). Bunun nedeni, ev kaynaklarının öğrenciler tarafından nasıl kullanıldığına bağlı olmaktadır. Alanyazına göre ev kaynaklarının etkili kullanılması, özellikle evdeki eğitsel kaynakların kullanımı (Arıkan, van de Vijver ve Yagmur, 2016; Tavşancıl ve Yalçın, 2015) öğrencilerin başarıları üzerinde olumlu bir etkiye sahiptir. TIMSS uygulamalarında eğitsel ev kaynakları değişkeni oluşturulurken evde bulunan kitap sayısı da ele alınmaktır (Martin ve diğ., 2016; Martin ve Mullis, 2012). Bu çalı̧̧mada da öğrencilerin doğrudan zihinsel süreçlerine katkı sağlayan sahip olunan kitap sayısının yaşla etkileşiminin başarı üzerinde olumlu etkisi ortaya konulmuştur. Göreli yaş etkisinin ortaya çıkmasının nedenlerinden biri olarak zihinsel gelişimin (Sykes, Bell ve Rodeiro, 2009) önemli olması da bu durumla örtüşmektedir. Öğrencilerin sosyoekonomik düzeyi, onların yetiştirilmesinde (Solli, 2017), özellikle okul başlamadan önce alacağı eğitimin niteliği üzerinde rol oynamaktadır (Frey, 2005). Öğrencilerin okul öncesi eğitimlerinin okula hazırbulunuşlarında önemli etkisi olduğu birçok araştırma tarafından ortaya konulmuştur (Taylor, Gibbs ve Slate, 2000). Bu anlamda, ögrencilerin ev kaynakları, sahip olduğu kitap sayısı ve bunların öğrenci tarafından nasıl kullanıldığı, öğrencilerin yaşları nedeniyle ortaya çıkacak olumsuzluklarda rol oynayabilir.

$\mathrm{Bu}$ araştırmada ortaya konulan sonuçlar, çalışmanın sınırlılıkları çerçevesinde değerlendirilmelidir. $\mathrm{Bu}$ çalışmanın sınırlılıklarından birisi çalışmanın göreli yaş etkisini kesitsel olarak incelemesidir. Öğrenciler üzerindeki göreli yaş etkisinin $4+4$ + 4 çerçevesinde boylamsal bir şekilde incelenmiş olması, ortaya konulacak sonuçlara dayalı yapılacak çıkarımların daha geçerli olmasını sağlayabilir. Alanyazına göre göreli yaş etkisinin ortaya çıkmasında ya da bu etkinin dezavantajlarının giderilmesinde okul öncesi eğitimin önemli olduğu bilinmektedir. Bu anlamda, TIMSS uygulamalarında Türkiye örneklemi için ilgili veriler bulunmamaktadır. $\mathrm{Bu}$ nedenle, çalışmada bu önemli değişkene ilişsin herhangi bir bulgu elde edilememiştir. Gelecek çalışmalarda bu değişkenin ele alınmasıyla önemli bulgulara ulaşılabilir.

Diğer eğitim paydaşları göreli yaş etkisinin başarı rolü üzerindeki etkisini göz önüne alarak sınıfta diğerlerine göre yaşı küçük olan öğrencilere ek eğitim programları geliştirebilir. Öğretmenlerin özellikle okulöncesi ve sınıf öğretmenlerinin istemeden de olsa bu öğrencilerin aleyhinde karar vermemesi için göreli yaş etkisi hakkında öğretmenlerde farkındalık yaratabilecek eğitimler düzenlenebilir. Bu 
öğretmenler, göreli yaş etkisinden kaynaklı dezavantajlı duruma düşebilecek öğrencilere uygun etkinlikler hazırlayabilirler. Bu anlamda bu öğrencilere yönelik yapılacak ek eğitim programları uygun olacaktır.

$\mathrm{Bu}$ çalışmada her iki TIMSS uygulamasında da olup dördüncü sınıf öğrencilerinin göreli yaş etkisinde rol oynayabilecek ikinci düzey bir değişken bulunmamaktadır. Bunun yanında, bu araştırmada ele alınan bölge değişkeninin TIMSS 2015 uygulamasında kırsal kesimde yer alan tüm okulların ikinci düzeyde kayıp veri olarak alınması, çalışmanın diğer bir sınırlılığıdır. Bu anlamda gelecek araştırmalarda, göreli yaş etkisinde rol oynayabilecek çeşitli ikinci düzey değişkenler ele alınarak farklı örneklemlerde göreli yaş etkisi incelenebilir.

\section{Kaynakça}

Allen, J., and Barnsley, R. (1993). Streams and tiers: The interaction of ability, maturity, and training in systems with age-dependent recursive selection. The Journal of Human Resources, 28(3), 649-659.

Arikan, S., van de Vijver, F., and Yagmur, K. (2016). Factors contributing to mathematics achievement differences of Turkish and Australian Students in TIMSS 2007 and 2011. Eurasia Journal of Mathematics, Science and Technology Education, 12, 2039-2059.

Aune, T. K., Pedersen, A. V., Ingvaldsen, R. P., and Dalen, T. (2017). Relative age effect and gender differences in physical education attainment in Norwegian school children. Scandinavian Journal of Educational Research, 61(3), 369-375,

Barnsley, R. H., Thompson, A. H., and Barnsley, P. E. (1985). Hockey success and birth-date: The relative age effect. Journal of the Canadian Association for Health, Physical Education and Recreation, 51, 23-28.

Bedard, K., and Dhuey, E. (2006). The persistence of early childhood maturity: International evidence of long-run age effects. The Quarterly Journal of Economics, 2006, 121(4), 1437-1472.

Borg, M. G., and Falzon, J. M. (1995). Birth date and sex effects on the scholastic attainment of primary schoolchildren: A cross-sectional study. British Educational Research Journal, 21(1), 61-74.

Browne, W. J., and Draper, D. (2006). A comparison of Bayesian and likelihoodbased methods for fitting multilevel models. Bayesian Analysis, 1, 473-514.

Cerit, Y., Akgün, A., Yıldız, K. ve Soysal, M. R. (2014). Yeni eğitim sisteminin (4+4+4) uygulanmasında yaşanan sorunlar ve çözüm önerileri (Bolu il örneği). Ĕ̈itim Bilimleri Araştırmaları Dergisi, 4(1), 59-82. 
Doğan, S., Uğurlu, C. T. ve Demir, A. (2014). 4+4+4 eğitim sisteminin okul paydaşlarına olumlu ve olumsuz etkilerinin yönetici görüşlerine göre incelenmesi. Gaziantep University Journal of Social Sciences, 13(1), 115-138.

Epçaçan, C. (2014). İlkokul ve ortaokul öğretmen ve yöneticilerinin 4+4+4 eğitim sistemine ilişkin görüşleri. Ekev Akademi Dergisi, 18(58), 505-522.

Frey, N. (2005). Retention, social promotion, and academic redshirting: What do we know and need to know? Remedial and Special Education, 26(6), 332-346.

Gledhill, J., Ford, T, and Goodman, R. (2002). Does Season of Birth matter? Research in Education, 68, 41-47.

Grondin, S,. Deshaies, P., and Nault, L. (1984). Trimestres de naissance et participation au hockey et au volleyball. La Revue Quebecoise de l'Activite Physique, 2, 97-103.

Güven, İ. (2012). Eğitimde $4+4+4$ ve Fatih Projesi yasa tasarısı = Reform mu? Illkögretim Online, 11(3), 556-577.

Güvendir, M. A. (2017). Uluslararası Öğrenci Değerlendirme Programında Öğrencilerin matematik okuryazarlıkları ile ev ve okul eğitim olanakları arasındaki ilişkinin belirlenmesi - (PISA 2012). Mersin Üniversitesi Eğitim Fakültesi Dergisi, 13(1), 94-109.

Heck, R. H., and Thomas, S. L. (2015). An introduction to multilevel modeling techniques: MLM and SEM approaches using Mplus. New York, NY: Routledge.

Hauck, A. L., and Finch Jr, A. J. (1993). The effect of relative age on achievement in middle school. Psychology in the Schools, 30(1), 74-79.

Huang, F. L. (2015). Birthdate effects and gifted program participation in kindergarten. Gifted Child Quarterly, 59(1), 14-22.

Liu, Y., Zumbo, B. D., and Wu, A. D. (2014). Relative importance of predictors in multilevel modeling. Journal of Modern Applied Statistical Methods, 13(1), 122.

Lodico, M. G., Spaulding, D. T., and Voegtle, K. H. (2006). Methods in educational research: From theory to practice. San Francisco, CA: Jossey-Bass.

Martin, M. O., Mullis, I. V. S., and Hooper, M. (Eds.). (2016). Methods and Procedures in TIMSS 2015. Retrieved from Boston College, TIMSS and PIRLS International Study Center website: http://timssandpirls.bc.edu/publications/timss/2015-methods.html

Martin, M.O. and Mullis, I.V.S. (Eds.). (2012). Methods and procedures in TIMSS and PIRLS 2011. Chestnut Hill, MA: TIMSS and PIRLS International Study Center, Boston College. 
Memişoğlu, S. P. ve İsmetoğlu, M. (2013). Zorunlu eğitimde $4+4+4$ uygulamasına iliş̧kin okul yöneticilerinin görüşleri. Eğitim ve Öğretim Araştırmaları Dergisi, 2(2), 14-25.

Milli Eğitim Bakalnlığı (2012). 12 yıllık zorunlu eğitime yönelik uygulamalar. $2012 / 20$ sayılı genelge. http://www.meb.gov.tr/haberler/2012/12YillikZorunluEgitimeYonelikGenelge. pdf. adresinden elde edilmiştir.

Musch, J., and Hay, R. (1999). The relative age effect in soccer: Cross-cultural evidence for a systematic discrimination against children born late in the competition year. Sociology of Sport Journal, 16, 54-64.

Muthén, L. K., and Muthén, B. O. (1998-2017). Mplus User's Guide (Eighth Edition). Los Angeles, CA: Muthén \& Muthén

Norbury, C. F., Gooch, D., Baird, G., Charman, T., Simonoff, E., and Pickles, A. (2016). Younger children experience lower levels of language competence and academic progress in the first year of school: Evidence from a population study. Journal of Child Psychology and Psychiatry, 57(1), 65-73.

Organisation for Economic Co-operation and Development (2014). PISA 2012 technical report. Paris: OECD Publications.

Sakic, M., Burusic, J., and Babarovic, T. (2012). The relation between school entrance age and school achievement during primary schooling: Evidence from Croatian. Primary schools. British Journal of Educational Psychology, 83(4), 651663.doi.org/10.1111/bjep.12000.

Smith, J. (2009). Can regression discontinuity help answer an age-old question in education? The effect of age on elementary and secondary school achievement. The B.E. Journal of Economic Analysis \& Policy, 9(1), 1-30.

Solli, I. F. (2017). Left behind by birth month. Education Economics, 25(4), 323-346.

Sprietsma, M. (2010). Effect of relative age in the first grade of primary school on long-term scholastic results: International comparative evidence using PISA 2003. Education Economics, 18(1), 1-32.

Sykes, E. D. A., Bell, J. F., and Rodeiro, C. V. (2009). Birthdate effects: A review of the literature from 1990-on. University of Cambridge Local Examinations Syndicate. Retrieved from http://www.cambridgeassessment.org.uk/ca/digitalAssets/169664_Cambridge_ Lit_Review_Birthdate_d3.pdf.

Tavşancıl, E., and Yalçın, S. (2015). A determination of Turkish student's achievement using hierarchical linear models in Trends in International Mathematics-Science Study (TIMSS) 2011. Anthropologist, 22(2), 390-396. 
Taylor, K. K., Gibbs, A. S., and Slate, J. R. (2000). Preschool attendance and kindergarten readiness. Early Childhood Education Journal, 27, 191-195.

Thompson, A. H., Barnsley, R. H., and Battle, J. (2004). The relative age effect and the development of self-esteem. Educational Research, 46(3), 313-320.

Thoren, K., Heinig, E., and Brunner, M. (2016) Relative age effects in mathematics and reading: Investigating the generalizability across students, time and classes. Frontiers in Psychology, 7(679), 1-12.

TIMSS and PIRLS International Study Center (2018). Retrieved from http://timssandpirls.bc.edu

TIMSS and PIRLS International Study Center (2018). Retrieved from https://timssandpirls.bc.edu/timss2011/international-database/

TIMSS and PIRLS International Study Center (2018). Retrieved from https://timssandpirls.bc.edu/timss2015/international-database/

Verachtert, P., De Fraine, B., Onghena, P., and Ghesquière, P. (2010). Season of birth and school success in the early years of primary education. Oxford Review of Education, 36(3), 285-306.

Wilson, G. (2000). The effects of season of birth, sex and cognitive abilities on the assessment of special educational needs. Educational Psychology, 20(2), 153166.

Zhong, S., Y. (2012). The Effects of Relative Age on Early Childhood Academic Achievement: How they Differ Between Gender and Change Across Time (Bachelor thesis). Stanford University. 


\title{
What Remains of The $4+4+4$ System in Turkey?: The Relative Age Effect On Student Achievement
}

\begin{tabular}{cccc}
\hline ARTICLE TYPE & Received Date & Accepted Date & Online First Date \\
Research Article & 11.26 .2018 & 02.18 .2019 & 02.19 .2019 \\
\hline
\end{tabular}

\author{
H. Çiğdem Yavuz iD 1 \\ Çukurova University
}

\begin{abstract}
It has been put forward by many empirical studies that the month of a student's birth is crucial in relation to their school achievement. Within this context, this study aimed to investigate whether there was a relative age effect on the mathematics and science achievement of fourthgrade Turkish students and how the relative age effect changed after the implementation of the $4+4+4$ system. In addition, the impact of the interaction of the students' ages with other factors of gender, home resources, and the number of books owned on student achievement was analyzed. The participants of the study comprised 10297 students, who were in the age range determined within the context of some criterion among Turkish students who participated in Trends in International Mathematics and Science Study (TIMSS) 2011 and TIMSS 2015. Multivariate multilevel modeling was utilized in the data analysis. At the student level, the interaction of the age variable with gender, the home resources, and the number of books owned was analyzed. The region variable was included in the model at the school level. In this context, it is determined that the relative age effect was observed in student achievement before and after the $4+4+4$, but this effect was found to be higher in 2015 . In other words, it can be expressed that the students' ages placed them at a disadvantage in 2015. Moreover, the interaction between age and home resources was determined to have a negative effect while the interaction between age and number of books owned had a positive effect on student achievement.
\end{abstract}

Keywords: Relative age effect, student achievement, $4+4+4$, TIMSS, multivariate multilevel modelling

\footnotetext{
${ }^{1}$ Corresponding Author: Res. Asst. Dr., Faculty of Education, Department of Educational Sciences, Email: hcyavuz@gmail.com, http://orcid.org/0000-0003-2585-3686
} 


\section{Purpose and Significance}

It has been put forward by many empirical studies that the month of a student's birth is crucial in relation to their school achievement (Aune, Pedersen, Ingvaldsen and Dalen, 2017; Haunk and Finch, 1993; Sprietsma, 2010; Thoren, Heinig and Brunner, 2016). According to these studies, a student born in the first months of the year appear to be in a more advantageous position compared to those born in the last months of that year. Within an academic year, the ages of the students are considered to be the same, the student's month of birth may offer them relatively more advantages or disadvantages compared with other students (Haunk and Finch, 1993). Thus, the relative age effect that occurs according to the group is also observed in education in a similar way as in other fields such as various sports branches (Aune, Pedersen, Ingvaldsen and Dalen, 2017; Huang, 2015; Sprietsma, 2010; Thoren, Heinig and Brunner, 2016; Verachtert, De Fraine, Onghena and Ghesquière, 2010).

The emergence of such relative age effect is argued in the literature to result from the difference in the students' levels in terms of intelligence, maturity, and potential (Sykes, Bell and Rodeiro, 2009). The reasons for these differences are also reported to vary according to the gender or sociocultural/socioeconomic status of students (Aune et al., 2017; Borg and Falzon, 1995; Musch and Hay, 1999; Solli, 2017; Wilson, 2000; Zhong, 2012).

Within the scope of the information provided by the related literature, many educational shareholders discussed the school starting date and age (Haunk and Finch, 1993). In Turkey, the age for starting school was reduced from 72 to 66 months in 2012 (Ministry of National Education [MNE], 2012). Together with the new regulation, compulsory education in Turkey was divided into three four-year stages $(4+4+4)$. The literature contains many studies that focus on the challenges and disadvantages of the new regulation encountered by educational shareholders (Cerit, Akgun, Yildiz and Soysal, 2014; Dogan, Ugurlu and Demir, 2014; Epcacan, 2014; Memisoglu and Ismetoglu, 2013). The most important issues concerned students being affected by the division of education into stages and changing the age at which they would start school. In particular, the change in the starting age of primary education, according to Guven (2012), may lead to irreversible damage to student achievement. Thus, it is important to determine whether the relative age effect does have a significant effect on Turkish students' achievement, especially for national literature and educational shareholders.

In the current study, the significance of the relative age effect was examined within the scope of the fourth-grade applications of the Trends in International Mathematics and Science Study (TIMSS). The relative age effect was examined in the achievement of two groups of fourth-grade students: those that entered school when the starting age was 72 months and participated in TIMSS 2011, and those who began school when the starting age was 66 months and participated in TIMSS 2015. In addition, the impact of the interaction of the students' ages with other factors of 
gender, home resources, and the number of books owned on student achievement was analyzed.

\section{Method}

The participants of the study comprised Turkish students who participated in TIMSS 2011 and TIMSS 2015. The students were chosen based on the information from the TIMSS 2011 and 2015 Turkish curriculum survey. There were 5,742 students who were eligible to start school in 2007 and participated in TIMSS 2011, and 4,555 students who were eligible to start school in 2011 and participated in TIMSS 2015. In this sense, their range of ages in terms of months were 113 to 125 in TIMSS 2011, and 111 to 119 in TIMSS 2015.

In the study, various procedures were undertaken to prepare the data sets before analysis. A new index variable was created for the home resources variable (homei) for each TIMSS application. The age variable (agem) of the participants included in the study was calculated.

Multivariate multilevel modeling was utilized in the data analysis. All the analyses were conducted using the Mplus 8 program. At the student level, the interaction of the age variable (agem) with gender (agem*ITSEX), the home resources (agem*homei), and the number of books owned (agem*ASBG04) was analyzed. The region variable was included in the model at the school level. The Pratt index (Liu, Zumbo, and $\mathrm{Wu}, 2014$ ) was calculated to show the relative importance of variables in predicting the dependent variable.

\section{Results}

Within the scope of the study, significant differences were found between the schools in terms of mathematics and science achievement in TIMSS 2011 and 2015 $(\mathrm{p}<.05)$. In TIMSS 2011, variance of within-school variability in mathematics was found to be 5631.92, while between-schools variability was 3043.71, within-group correlation coefficient was .34; variance of within-school variability in science was found to be 5464.26, while between-schools variability was 2898.29 , and withingroup correlation coefficient was .33. In TIMSS 2015, variance of within-school variability in mathematics was found to be 5420.36 , while between-schools variability was 3321.68, within-group correlation coefficient was .38; variance of within-school variability in mathematics in science was found to be 5343.47, while between-schools variability was 2813.29, and within-group correlation coefficient was found as .35.

In both TIMSS applications, the relative age effect on students' achievement in both mathematics and science was statistically significant. In TIMSS 2011, the Pratt index of the relative age effect was found to be .06 for mathematics and .05 for science. These values indicate that the relative age effect is not an important predictor in both areas. However, in TIMSS 2015, the Pratt index of the relative age effect was .17 and .24 for mathematics and science, respectively; thus, the Pratt index regarding these variables was higher than .167 in TIMSS 2015 (Liu, Zumbo and Wu, 2014), 
demonstrating that the relative age effect is an important predictor on student achievement. In this context, the fact that one student is one month older than the other students in TIMSS 2015 increases the average mathematics achievement by approximately 3.32 points and the average science achievement by 3.58 points. Therefore, it can be stated that the relative age effect has a statistically significant impact on student achievement in TIMSS 2011, but this is not important in practice while the relative age effect has a significant and important effect on student achievement in TIMSS 2015 both statistically and practically. In this sense, it can be stated that especially the students who were older starting school in terms of months within the scope of the $4+4+4$ system had higher TIMSS achievement than the other students in 2015.

\section{Discussion and Conclusions}

This study aimed to investigate whether there was a relative age effect on the mathematics and science achievement of fourth-grade Turkish students and how the relative age effect changed after the implementation of the 4+4+4 system. In this context, it is determined that the relative age effect was observed in student achievement before and after the $4+4+4$, but this effect was found to be higher in 2015. In other words, it can be expressed that the ages of the students who were younger than their peers placed them at a disadvantage in 2015. Besides, the effect of the interaction of age, gender, home resources, and number of books owned on students' mathematics and science achievement were also examined in this study. According to this, the interaction between age and home resources was determined to have a negative effect while the interaction between age and number of books owned had a positive effect on student achievement.

In literature, the relative age effect on the achievement of students can be seen in many countries in which the school term starts in September as in Turkey (Bedard and Dhuey, 2006; Thoren, Heinig and Brunner, 2016; Sprietsma, 2010). The regulation that came with $4+4+4$ regarding the school starting age in Turkey can be presented as the reason for the increase in the relative age effect from 2011 to 2015. The fact that a group of students are disadvantaged due to the relative age effect originates from the fact that the related group is physically and psychologically relatively behind the others (Sykes, Bell and Rodeiro, 2009; Solli, 2017). In this sense, with the new age regulation introduced by $4+4+4$, the emergence of such problems may be more likely to occur.

There was no significant association between age and gender in the study; i.e., the age of the students' being younger or older in terms of month does not create a significant difference in mathematics and science based on gender. In the literature, there was no significant relationship between gender and age in some studies (Haunk and Finch, 1993; Solli, 2017), whereas in other studies, the relative age effect was found to be more effective for girls (Aune et al., 2015; Borg and Falzon, 1995; Smith, 2009). 
The negative interaction between age and home resources in the study may be due to home resources (such as internet, etc.) which may show an inverse relationship especially with the achievement of Turkish students. This situation is supported by studies in the national literature (see Guvendir, 2017), with the reason being related to how home resources are used by students. For example, the positive effect of the interaction between age and number of books owned that contribute directly to the mental processes of the students is shown in this study. The importance of intellectual development, which is one of the reasons for the emergence of the relative age effect (Sykes, Bell and Rodeiro, 2009), coincides with this situation. The socioeconomic level of students plays a role in their upbringing (Solli, 2017), and especially in the quality of the preschool education they receive (Frey, 2005). It has been demonstrated by many studies that pre-school education has a significant impact on the school readiness (Taylor, Gibbs and Slate, 2000). In this sense, students' home resources, number of books owned, and how they are used by the student can compensate for the young age. 